\title{
Coercion and psychiatric rehabilitation: a conceptual and ethical analysis
}

\author{
Abraham Rudnick
}

\author{
Address: University of Western Ontario, Departments of Psychiatry and Philosophy, Regional Mental Health Care, 850 Highbury Avenue, London \\ Ontario N6A4H1, Canada \\ from WPA Thematic Conference. Coercive Treatment in Psychiatry: A Comprehensive Review \\ Dresden, Germany. 6-8 June 2007 \\ Published: 19 December 2007
}

BMC Psychiatry 2007, 7(SuppI I):S22 doi:10.1 186/I47I-244X-7-SI-S22

This abstract is available from: http://www.biomedcentral.com/I47I-244X/7/SI/S22

(c) 2007 Rudnick; licensee BioMed Central Ltd.

Psychiatric rehabilition is the theory and practice of assisting persons with severe mental illnesses achieve and maintain goals. This consists of personal skills training and environmental accommodations, aimed at the person with the mental illness fulfilling roles. Although coercion in relation to psychiatric treatment has been discussed at length, coercion has not been sufficiently discussed in relation to psychiatric rehabilitation [1]. The objective of this paper is to conduct a conceptual and ethical analysis of coercion in psychiatric rehabilitation. Although the leading theoretical approach to psychiatric rehabilitation is client-centered, there is also a more paternalistic approach to psychiatric rehabilitation [2]. Coercion is conceptually incompatible with client-centered psychiatric rehabilition, as coercion can be defined as the restriction or modification of a person's range of choice or actual choice by one or more other persons, whereas client-centered psychiatric rehabilitation aims to preserve or expand the mentally ill person's range of choice or actual choice by means of one or more other persons. Coercion is conceptually compatible with paternalistic psychiatric rehabilitation, but it is ethically questionable in relation to psychiatric rehabilitation, as in this context it involves a change of goals and roles, which can be much more intrusive and forceful than coercion in relation to treatment, psychiatric or other. To the extent that psychiatric rehabilitation and treatment are integrated, psychiatric rehabilitation may have to accommodate some coercion when psychiatric treatment requires it, such as in situations of considerable physical risk due to the mental illness.

\section{References}

I. Rudnick A: The goals of psychiatric rehabilitation: an ethical analysis. Psychiatr Rehabil j 2002, 25:3 I0-3I3.
2. Siris SG, Bermanzohn PC: Two models of psychiatric rehabilitation: a need for clarity and integration. J Psychiatr Pract 2003. 9:17|-175. 